Article

\title{
Incubation under Climate Warming Affects Behavioral Lateralisation in Port Jackson Sharks
}

\author{
Catarina Vila Pouca * (D), Connor Gervais ${ }^{(\mathbb{D})}$, Joshua Reed ${ }^{(\mathbb{D})}$ and Culum Brown ${ }^{(\mathbb{D})}$ \\ Department of Biological Sciences, Macquarie University, Sydney 2109, Australia; \\ connor-robert.gervais@students.mq.edu.au (C.G.); joshua.reed@students.mq.edu.au (J.R.); \\ culum.brown@mq.edu.au (C.B.) \\ * Correspondence: catarina.vilapouca@mq.edu.au
}

Received: 10 May 2018; Accepted: 25 May 2018; Published: 28 May 2018

\begin{abstract}
Climate change is warming the world's oceans at an unprecedented rate. Under predicted end-of-century temperatures, many teleosts show impaired development and altered critical behaviors, including behavioral lateralisation. Since laterality is an expression of brain functional asymmetries, changes in the strength and direction of lateralisation suggest that rapid climate warming might impact brain development and function. However, despite the implications for cognitive functions, the potential effects of elevated temperature in lateralisation of elasmobranch fishes are unknown. We incubated and reared Port Jackson sharks at current and projected end-of-century temperatures and measured preferential detour responses to left or right. Sharks incubated at elevated temperature showed stronger absolute laterality and were significantly biased towards the right relative to sharks reared at current temperature. We propose that animals reared under elevated temperatures might have more strongly lateralized brains to cope with deleterious effects of climate change on brain development and growth. However, far more research in elasmobranch lateralisation is needed before the significance of these results can be fully comprehended. This study provides further evidence that elasmobranchs are susceptible to the effects of future ocean warming, though behavioral mechanisms might allow animals to compensate for some of the challenges imposed by climate change.
\end{abstract}

Keywords: laterality; climate change; temperature; development; elasmobranchs

\section{Introduction}

Climate change has been identified as one of the major human-induced environmental impacts to ecosystems worldwide [1]. The average temperature of the upper layers of the ocean has increased by $1.0^{\circ} \mathrm{C}$ over the past 120 years, and is predicted to increase by $1-3^{\circ} \mathrm{C}$ over the next century if the current trajectory of greenhouse gas emissions is maintained [1,2]. In addition, oceanic carbon dioxide $\left(\mathrm{CO}_{2}\right)$ levels have now reached historically high levels [3]. Such rapid changes in important environmental parameters will considerably impact marine ecosystems.

Elevated temperatures and $\mathrm{CO}_{2}$ levels in the ocean can significantly impair sensory functions and alter critical behavior in teleost fish and elasmobranchs. For example, coral reef fish and benthic sharks exposed to elevated $\mathrm{CO}_{2}$ levels showed impaired olfactory and auditory responses, important for predator/prey recognition and homing behavior [4-9]. Additionally, exposure to elevated temperatures resulted in higher developmental rate and metabolism, as well as limited growth, aerobic scope, reproductive output, and foraging [8-12]. Whereas highly mobile species will likely shift their distributions poleward [13], less mobile species will have to cope with these changes through rapid evolution or phenotypic plasticity. Ectotherms are especially vulnerable to global warming because their body temperature and basic physiological functions are regulated by the external environment. 
In addition, many elasmobranch species are oviparous and have long gestation periods of several months, so embryos will be exposed to prevailing environmental conditions and have little choice other than to adapt or die. One mechanism used by more sedentary species to compensate for the increase in developmental and metabolic rates is the reallocation of energy resources during development, which is expected to affect highly metabolically expensive systems, such as neural development and processing [14-16]. The detrimental effects in a range of sensory modalities and behaviors have already been observed in fish (e.g., [4,6]), suggesting that predicted climate change conditions might disproportionately impact brain development and function.

Behavioral lateralisation, the tendency to favor the left or right side in a given context, results from a functional asymmetry between the two hemispheres of the brain [17-20]. Cerebral and behavioral lateralisation are widespread in the animal kingdom and have been well studied in teleost fish [17,21]. Teleosts generally prefer to use the left eye and right hemisphere to process biologically relevant stimuli, such as predators or potential mates, and emotional responses, such as fear and aggression, whereas the right eye and left hemisphere are generally linked to stimuli categorisation and object manipulation. Nonetheless, we often see species, population, or individual differences that arise through a mixture of genetic and experiential effects [22-25].

Laterality in elasmobranchs is understudied, with only two studies investigating behavioral lateralisation in benthic sharks [26,27]. Byrnes, Vila Pouca and Brown [26] observed individual levels of laterality bias in rotational swimming and T-maze turn preference in juvenile Port Jackson sharks, with females more strongly lateralised than males, and Green and Jutfelt [27] reported a population-level laterality bias in double T-maze turn in small-spotted catsharks. Lateralisation of behavior and cognitive functions have been suggested to offer selective advantages [19,28]. For example, laterality enhances schooling behavior that can have important fitness-related implications in foraging and anti-predator behavior [29]. Schools of lateralised fish were more cohesive and coordinated than schools of non-lateralised fish [30], and individuals tended to take positions in the school that correspond to their visual hemifield preferences for observing conspecifics [25]. A laterality bias might also provide them with advantages in multitasking situations, such as foraging while being vigilant to predators, and enhancing cognitive efficiency [28,31-33].

Since behavioral lateralisation is an expression of brain function, it can be used as a barometer of normal brain development and function in some contexts, namely exposure or development under climate change conditions. An increasing number of studies have reported the impact of increased $\mathrm{CO}_{2}$ levels and elevated temperature on behavioral lateralisation in some teleost species, though with varying direction and magnitude [34-38]. The behavioral effects of elevated $\mathrm{CO}_{2}$ levels in teleosts seem to stem from a dysfunction of the GABA-A neurotransmitter receptor in the brain [39]. In elasmobranchs, only one study investigated the effects of future climate change conditions on behavioral lateralisation [27]. Small-spotted catsharks aged 4-24 months exposed to increased $\mathrm{CO}_{2}$ for as little as four hours showed stronger absolute lateralisation at the population level when compared with control individuals [27]. Such short-term responses are likely indicative of phenotypic plasticity and might mimic responses to brief environmental changes (e.g., day vs. night or intertidal zone conditions). The impacts of long-term exposure to elevated temperature on cerebral lateralisation, especially during critical developmental periods, have not yet been assessed in elasmobranchs. With so many reported consequences on development and physiology in elasmobranchs [8,9,40,41], it is likely that rapid climate warming might also impact brain function in this group. In the present study, we tested the hypothesis that the predicted end-of-century temperature during embryogenic and hatchling development affects behavioral lateralization in benthic shark species. 


\section{Materials and Methods}

\subsection{Ethics Statement}

Egg collection occurred under New South Wales Fisheries permit P08/0010-4.2. The experiments were approved by the Macquarie University Animal Ethics Committee (ARA 2016-027). All animals were euthanised at the end of the experiment with a lethal dose of MS-222 (tricaine methane-sulfonate; $1.5 \mathrm{~g} / \mathrm{L}$ seawater) for brain anatomy studies, to be reported in a separate paper.

\subsection{Egg Collection and Incubation}

We collected Port Jackson shark eggs via snorkeling from Jervis Bay, NSW. Females lay their eggs in shallow rocky reefs during late winter, mostly during August and September [42]. Freshly laid egg capsules are clean, soft, pliable, and olive green in color, but become brittle after two weeks and change to a dark brown color in 3-5 weeks [43] enabling an estimation of laying date. Under ambient conditions, embryos have a long incubation period of 10-11 months [43]. Eggs were collected on 11 October and 2 November 2016 and we estimate all had been laid recently, within 6 weeks of collection. Eggs were transported to Macquarie University, Sydney Australia, and held in a temperature-controlled laboratory until hatching. The eggs were placed in $40 \mathrm{~L}$ tanks containing natural filtered seawater and the temperature was maintained using a custom-design Seawater Environmental Control Mixing Chamber. Following transport, eggs were left to rest for 7 days, then the temperature was steadily increased by $0.5^{\circ} \mathrm{C} /$ day to the elevated temperature treatment in half of the tanks. We randomly divided eggs among the two treatments: a control temperature treatment $(C ; n=12)$ incubated at $20.6 \pm 0.5^{\circ} \mathrm{C}$, consistent with the annual average maximum temperature in Jervis Bay; and an elevated temperature treatment $(\mathrm{ET} ; n=12)$ incubated at $23.6 \pm 0.5^{\circ} \mathrm{C}$, representing the end of century projected sea-surface temperature increase under the representative concentration pathway (RCP) 8.5 climate model [1]. The $\mathrm{CO}_{2}$ of the system reflected ambient conditions ( $\left.\rho \mathrm{CO}_{2} \sim 418 \mathrm{ppm}\right)$.

When the egg capsules' mucous plugs opened, approximately four months into development, the embryos were removed from the egg and placed in individual containers within the housing tank for close monitoring.

\subsection{Husbandry and Rearing}

Approximately one month after hatching (stage 15 [43]; external yolk completely exhausted, internal yolk virtually depleted, and disappearance of slime coat), individuals were moved to the Sydney Institute of Marine Science (SIMS). Sharks were housed in groups of six animals in $1000 \mathrm{~L}$ tanks maintained at incubation temperatures using submersible heaters (one $2000 \mathrm{~W}$ titanium stick heater or four $300 \mathrm{~W}$ AquaOne glass heaters). Tanks had a continuous supply of fresh seawater pumped directly from Sydney harbor, aeration, and polyvinyl chloride (PVC) structures and fake kelp to provide shelter and enrichment. Tanks were scrubbed clean at least once a week. The room had a natural light/dark cycle.

Immediately after hatching, Port Jackson sharks were weighed, measured (total length, TL), and individually tagged beneath the dorsal fin (Passive Integrated Nano-Transponder, Trovan ${ }^{\circledR}$ ID-100A/1.25, Microchips Australia Pty Ltd., Victoria, Australia). Sharks were fed ad libitum on a mixed diet of squid, cuttlefish, whitebait, and prawns three times per week.

Five sharks from the elevated temperature treatment did not survive the first month after hatching (three deaths and two were euthanised because they were not feeding). We therefore started the procedure with seven ET and twelve C sharks, 58.3 and 100\% of our initial sample size for each group, respectively. The median age of the test subjects from the ET group was 63.5 days post-hatching compared with 85.5 of the $\mathrm{C}$ group. 


\subsection{Procedure}

The experimental tank $(180 \times 100 \times 40 \mathrm{~cm}$; Figure 1$)$ was maintained at incubation temperature using four to six $300 \mathrm{~W}$ AquaOne glass heaters. For four days prior to the laterality assay, sharks were allowed to familiarise with the experimental tank to allow them to overcome any stress associated with moving between the housing and experimental tanks and being in a novel environment. During the familiarisation phase, the shark could swim freely in the tank for a 30-min period after which it was fed $2 \%$ of its body weight.

To assess behavioral laterality, sharks were tested individually in a detour test using a Y-maze [44]. The test consisted of 10 trials conducted on a single day. For each trial, the subject was ushered down a corridor and its turn direction at the end of the maze was recorded. Based on results from a pilot study, a small piece of food was placed behind the partition at the end of the corridor and individuals were fed at the end of the 5th and 10th trials to encourage directed swimming along the maze and ensure motivation in the task. After each run, the shark was temporarily constrained in the choice zone. The subject was then released and allowed to swim down the runway in the opposite direction. This approach reduces handling stress and reduces the possibility of extraneous cues inducing side biases. The shark was allowed $30 \mathrm{~s}$ to recover between runs.

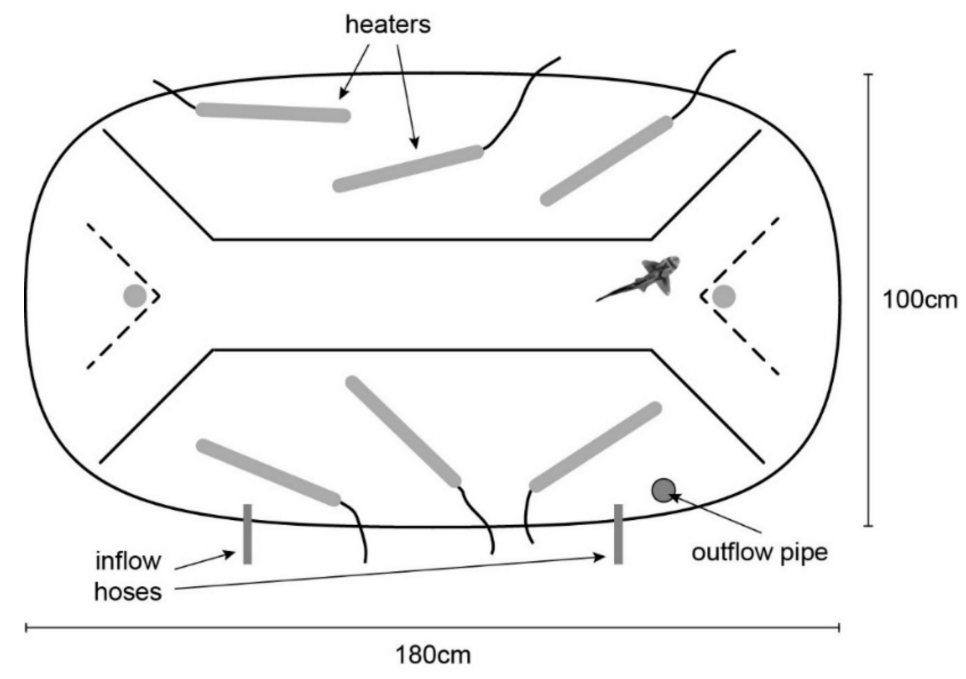

Figure 1. Diagram of the experimental tank.

\subsection{Data Analysis}

We calculated laterality index as follows: $\mathrm{L}_{\mathrm{I}}=$ (number of right turns - number of left turns)/(total number of turns). $\mathrm{L}_{\mathrm{I}}$ is a continuous value from -1 to 1 , in which a positive score indicated a preference for rightward turns and a negative score indicated a preference for leftward turns. Laterality strength $\left(\mathrm{L}_{\mathrm{S}}\right)$ was calculated by taking the absolute value of $\mathrm{L}_{\mathrm{I}}$.

Statistical analyses were conducted in R v. 3.4.3 [45]. We used non-parametric tests due to low sample sizes. Separate Mann-Whitney $U$ tests were used to compare $\mathrm{L}_{\mathrm{I}}$ and $\mathrm{L}_{\mathrm{S}}$ scores between $\mathrm{C}$ and ET individuals, and to test if sharks within each group were significantly lateralised (distribution with $\mu \neq 0$ ).

\section{Results}

Sharks from the elevated temperature treatment $(\mathrm{ET})$ showed stronger absolute laterality $\left(\mathrm{L}_{\mathrm{S}}\right)$ compared to control temperature $(C)$ sharks (Figure 2a; $W=19, P=0.047$ ), along with higher laterality index $\left(\mathrm{L}_{\mathrm{I}}\right)$ values (Figure $2 \mathrm{~b} ; \mathrm{W}=10.5, P=0.0067$ ). ET sharks displayed a significant rightward bias $(\mathrm{V}=28, P=0.021)$, whereas $\mathrm{C}$ sharks showed no population-level preference for either side $(\mathrm{V}=12.5$, $P=0.746)$. Individual turn preferences are provided in Table 1. 
We examined the possible effect of age within the control group and found no relationship between age at testing and $\mathrm{L}_{\mathrm{I}}$ (d.f. $=10, t=-0.06, P=0.953, \mathrm{R}^{2}=0.00036$ ).

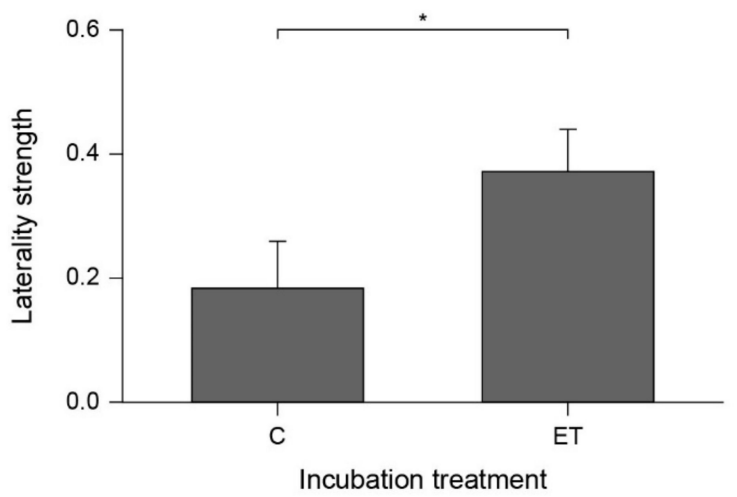

(a)

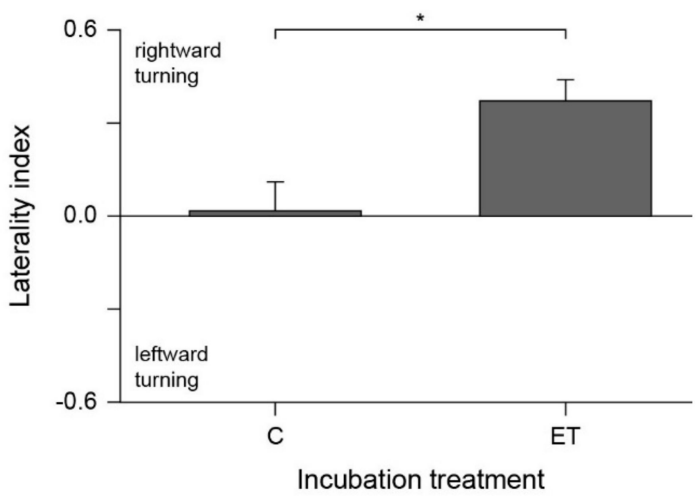

(b)

Figure 2. (a) Laterality strength (group mean \pm SEM) and (b) laterality index (group mean \pm SEM) in sharks incubated at control temperature $(C ; n=12)$ or elevated temperature $(E T ; n=7)$.

Table 1. Summary information on experimental subjects and individual left or right turn preference in the detour task.

\begin{tabular}{cccccccc}
\hline Shark ID & Sex & Weight $(\mathbf{g})$ & Treatment & \# Right Turns & \# Left Turns & L $_{\mathbf{I}}$ & $\mathbf{L}_{\mathbf{S}}$ \\
\hline C489 & M & 86 & C & 1 & 9 & -0.8 & 0.8 \\
C451 & M & 87 & C & 4 & 6 & -0.2 & 0.2 \\
C430 & M & 81 & C & 5 & 5 & 0 & 0 \\
C437 & M & 70 & C & 5 & 5 & 0 & 0 \\
C456 & F & 53 & C & 5 & 5 & 0 & 0 \\
C469 & M & 101 & C & 5 & 5 & 0 & 0 \\
C492 & F & 79 & C & 5 & 5 & 0 & 0 \\
C500 & F & 89 & C & 5 & 5 & 0 & 0 \\
C407 & M & 83 & C & 6 & 4 & 0.2 & 0.2 \\
C452 & F & 76 & C & 6 & 4 & 0.2 & 0.2 \\
C459 & M & 94 & C & 6 & 4 & 0.2 & 0.2 \\
C460 & F & 95 & C & 8 & 2 & 0.6 & 0.6 \\
ET455 & M & 64 & ET & 6 & 4 & 0.2 & 0.2 \\
ET369 & M & 50.5 & ET & 6 & 4 & 0.2 & 0.2 \\
ET373 & F & 59 & ET & 6 & 4 & 0.2 & 0.2 \\
ET480 & M & 64.5 & ET & 7 & 3 & 0.4 & 0.4 \\
ET400 & F & 78.5 & ET & 7 & 3 & 0.4 & 0.4 \\
ET433 & F & 79 & ET & 8 & 2 & 0.6 & 0.6 \\
ET468 & F & 62 & ET & 8 & 2 & 0.6 & 0.6 \\
\hline
\end{tabular}

Note: $\mathrm{M}$, male; F, female; $\mathrm{C}$, control temperature; ET, elevated temperature; $\mathrm{L}_{\mathrm{I}}$, Laterality index; $\mathrm{L}_{\mathrm{S}}$, Laterality strength.

\section{Discussion}

In this study, we showed that incubation the temperatures predicted for the end of the century affect behavioral lateralisation in Port Jackson sharks. This is the first documented case of a change in lateralised behavior induced by elevated temperature in any elasmobranch. Our hatchling sharks that were incubated and reared in elevated temperature showed stronger absolute laterality and a rightward bias compared with control individuals. Byrnes, Vila Pouca and Brown [26] observed high individual variation in laterality in wild-caught juvenile Port Jackson sharks similar to our control group, suggesting the results from our sharks reared at current ocean temperature in captivity reflect those in wild populations and were not influenced by captive rearing.

The shift in laterality to the right observed in the present study was not clearly due to plastic responses during development or the deaths of left biased or non-lateralised sharks 
during early ontogeny ( $42 \%$ of sharks reared in elevated temperatures died prior to testing). Behavioral lateralization, in particular handedness, is linked to immune response in humans, rodents, and dogs [46-48]. Immune responses might possibly differ between our two groups. However, to the best of our knowledge, the link between immune competency and lateralisation had not yet been investigated in teleosts or elasmobranchs. Elevated temperature significantly increased developmental rates and metabolism [8,9], with associated costs in terms of energy allocation to growth and physiological processes (e.g., [40]). Therefore, stronger lateralisation may arise as an energy saving mechanism. Functional asymmetries in the brain are thought to enable separate and parallel information processing in each hemisphere, which might increase the brain's capacity to perform simultaneous processing resulting in enhanced cognitive efficiency $[21,28]$. Neural processing is metabolically expensive; thus, higher parallel processing abilities could allow animals to save energy during brain development and information processing without compromising function. We therefore predict that animals reared under elevated temperatures might have smaller but more strongly lateralized brains. Interestingly, juvenile small-spotted catsharks exposed short-term to elevated $\mathrm{CO}_{2}$ levels showed stronger absolute laterality in a detour task [27]. Laterality can vary with age [49,50], but we examined the possible effect of age within the control group and found no correlation. It is worth noting that the variation in age within the control group was 35 days, which covers the average age difference between the control and elevated temperature treatments. Future research is needed to determine if laterality varies with age in sharks, perhaps over larger time frames. Regardless of the mechanism, it is apparent that climate change will impact elasmobranchs and the early developmental stages are particularly vulnerable, so further work is required specifically in the context of brain development and cognition under future climate scenarios.

With so few studies investigating laterality in elasmobranchs, commenting on the expected variability at the population or individual level is difficult, let alone on context-specific individual variation. Teleost fish show high variability in laterality strength and direction at the individual, population, and species level [23,44,51]. Additionally, laterality in teleosts has been linked to life history traits and environmental variables [52,53]. Fish from high predation areas, for example, showed stronger laterality than those from low predation areas and this has been linked to schooling behavior in several species $[23,25,30,51]$. To further complicate the situation, exposure to elevated temperature or $\mathrm{CO}_{2}$ levels resulted in varying directions and magnitude of change in laterality in different teleosts [34-38]. Some of these different effects might be due to the context of the task or a consequence of altered emotional states of the animal. For example, Domenici, Allan, Watson, McCormick and Munday [35] observed a reversal from right-turning bias in damselfish detouring around an opaque barrier to a left-turning bias when exposed to elevated $\mathrm{CO}_{2}$ levels. The authors suggested that elevated stress could induce this shift since stressed animals predominantly use the right hemisphere to control motor functions $[35,54]$. This was also possibly true in the present study, but we assumed that Port Jackson sharks predominantly use the left hemisphere to control motor function when under stress. Further studies are required to determine if this is the case.

\section{Conclusions}

To conclude, this study provides strong evidence that predicted end-of-century temperature affects behavioural lateralisation in sharks. The combination of elevated $\mathrm{CO}_{2}$ and temperature might have synergistic effects on laterality. We propose that enhanced lateralisation could help animals cope with the deleterious effects of climate change on development and growth. Evidently, far more research is needed in multiple elasmobranch species to provide an adequate picture of brain lateralisation in elasmobranchs to test this hypothesis. Future studies should combine laterality and cognitive tasks to assess if cognitive functions in elasmobranchs are lateralised, and evaluate the effect of climate change conditions on cognitive performance.

Author Contributions: Conceptualisation: C.V.P., C.G. and C.B.; Methodology: C.G., C.V.P. and C.B.; Investigation: C.G., C.V.P. and J.R.; Analysis: C.V.P.; Writing: C.V.P. and C.B. 
Acknowledgments: This research was funded by the Department of Biological Sciences at Macquarie University, and C.V.P. was supported by an Endeavour Postgraduate (PhD) Scholarship. We thank the members and interns of The Fish Lab and staff at SIMS, in particular Andrew Niccum, for husbandry and aquarium maintenance assistance.

Conflicts of Interest: The authors declare no conflict of interest.

\section{References}

1. Collins, M.; Knutti, R.; Arblaster, J.; Dufresne, J.-L.; Fichefet, T.; Friedlingstein, P.; Gao, X.; Gutowski, W.; Johns, T.; Krinner, G. Long-term climate change: Projections, commitments and irreversibility. In Climate Change 2013: The Physical Science Basis; IPCC Working Group I Contribution to AR5; Cambridge University Press: Cambridge, UK; New York, NY, USA, 2013; pp. 1029-1136.

2. Pörtner, H.-O.; Karl, D.M.; Boyd, P.W.; Cheung, W.; Lluch-Cota, S.E.; Nojiri, Y.; Schmidt, D.N.; Zavialov, P.O.; Alheit, J.; Aristegui, J. Ocean systems. In Climate Change 2014: Impacts, Adaptation, and Vulnerability. Part A: Global and Sectoral Aspects; Contribution of Working Group II to the Fifth Assessment Report of the Intergovernmental Panel on Climate Change; Cambridge University Press: Cambridge, UK; New York, NY, USA, 2014; pp. 411-484.

3. Stocker, T.F.; Qin, D.; Plattner, G.-K.; Alexander, L.V.; Allen, S.K.; Bindoff, N.L.; Bréon, F.-M.; Church, J.A.; Cubasch, U.; Emori, S. Climate Change 2013: The Physical Science Basis; Contribution of Working Group I to the Fifth Assessment Report of the Intergovernmental Panel on Climate Change; Cambridge University Press: Cambridge, UK; New York, NY, USA, 2013; pp. 33-115.

4. Cripps, I.L.; Munday, P.L.; McCormick, M.I. Ocean acidification affects prey detection by a predatory reef fish. PLoS ONE 2011, 6, e22736. [CrossRef] [PubMed]

5. Munday, P.L.; Cheal, A.J.; Dixson, D.L.; Rummer, J.L.; Fabricius, K.E. Behavioural impairment in reef fishes caused by ocean acidification at $\mathrm{CO}_{2}$ seeps. Nat. Clim. Chang. 2014, 4, 487. [CrossRef]

6. Simpson, S.D.; Munday, P.L.; Wittenrich, M.L.; Manassa, R.; Dixson, D.L.; Gagliano, M.; Yan, H.Y. Ocean acidification erodes crucial auditory behaviour in a marine fish. Biol. Lett. 2011, 7, 917-920. [CrossRef] [PubMed]

7. Dixson, D.L.; Munday, P.L.; Jones, G.P. Ocean acidification disrupts the innate ability of fish to detect predator olfactory cues. Ecol. Lett. 2010, 13, 68-75. [CrossRef] [PubMed]

8. Rosa, R.; Baptista, M.; Lopes, V.M.; Pegado, M.R.; Ricardo Paula, J.; Trübenbach, K.; Leal, M.C.; Calado, R.; Repolho, T. Early-life exposure to climate change impairs tropical shark survival. Proc. R. Soc. B Biol. Sci. 2014, 281. [CrossRef] [PubMed]

9. Pistevos, J.C.; Nagelkerken, I.; Rossi, T.; Olmos, M.; Connell, S.D. Ocean acidification and global warming impair shark hunting behaviour and growth. Sci. Rep. 2015, 5, 16293. [CrossRef] [PubMed]

10. Donelson, J.M.; Munday, P.L.; McCormick, M.I.; Pankhurst, N.W.; Pankhurst, P.M. Effects of elevated water temperature and food availability on the reproductive performance of a coral reef fish. Mar. Ecol. Prog. Ser. 2010, 401, 233-243. [CrossRef]

11. Munday, P.L.; Kingsford, M.J.; O'Callaghan, M.; Donelson, J.M. Elevated temperature restricts growth potential of the coral reef fish acanthochromis polyacanthus. Coral Reefs 2008, 27, 927-931. [CrossRef]

12. Nilsson, G.E.; Crawley, N.; Lunde, I.G.; Munday, P.L. Elevated temperature reduces the respiratory scope of coral reef fishes. Glob. Chang. Biol. 2009, 15, 1405-1412. [CrossRef]

13. Perry, A.L.; Low, P.J.; Ellis, J.R.; Reynolds, J.D. Climate change and distribution shifts in marine fishes. Science 2005, 308, 1912-1915. [CrossRef] [PubMed]

14. Soengas, J.L.; Aldegunde, M. Energy metabolism of fish brain. Comp. Biochem. Physiol. Part B Biochem. Mol. Biol. 2002, 131, 271-296. [CrossRef]

15. Brown, C. Experience and learning in changing environments. In Behavioural Responses to a Changing World: Mechanisms and Consequences; Candolin, U., Wong, B.B., Eds.; Oxford University Press: Oxford, UK, 2012.

16. Sheridan, J.A.; Bickford, D. Shrinking body size as an ecological response to climate change. Nat. Clim. Chang. 2011, 1, 401. [CrossRef]

17. Rogers, L.J.; Vallortigara, G.; Andrew, R.J. Divided Brains: The Biology and Behaviour of Brain Asymmetries; Cambridge University Press: Cambridge, UK, 2013. 
18. Vallortigara, G.; Versace, E. Laterality at the neural, cognitive, and behavioral levels. In Apa Handbook of Comparative Psychology: Basic Concepts, Methods, Neural Substrate, and Behavior, Vol. 1; American Psychological Association: Washington, DC, USA, 2017; pp. 557-577.

19. Vallortigara, G.; Rogers, L.J. Survival with an asymmetrical brain: Advantages and disadvantages of cerebral lateralization. Behav. Brain Sci. 2005, 28, 575-588. [CrossRef] [PubMed]

20. Rogers, L.J.; Andrew, R. Comparative Vertebrate Lateralization; Cambridge University Press: Cambridge, UK, 2002.

21. Bisazza, A.; Brown, C. Lateralization of cognitive functions in fish. In Fish Cognition and Behavior; Wiley: Oxford, UK, 2011; pp. 298-324.

22. Dadda, M.; Bisazza, A. Lateralized female topminnows can forage and attend to a harassing male simultaneously. Behav. Ecol. 2006, 17, 358-363. [CrossRef]

23. Bisazza, A.; Cantalupo, C.; Capocchiano, M.; Vallortigara, G. Population lateralisation and social behaviour: A study with 16 species of fish. Later. Asymmet. Body Brain Cogn. 2000, 5, 269-284. [CrossRef] [PubMed]

24. Bisazza, A.; de Santi, A. Lateralization of aggression in fish. Behav. Brain Res. 2003, 141, 131-136. [CrossRef]

25. Bibost, A.-L.; Brown, C. Laterality influences schooling position in rainbowfish, melanotaenia spp. PLoS ONE 2013, 8, e80907. [CrossRef] [PubMed]

26. Byrnes, E.E.; Vila Pouca, C.; Brown, C. Laterality strength is linked to stress reactivity in port jackson sharks (heterodontus portusjacksoni). Behav. Brain Res. 2016, 305, 239-246. [CrossRef] [PubMed]

27. Green, L.; Jutfelt, F. Elevated carbon dioxide alters the plasma composition and behaviour of a shark. Biol. Lett. 2014, 10, 20140538. [CrossRef] [PubMed]

28. Rogers, L.J.; Zucca, P.; Vallortigara, G. Advantages of having a lateralized brain. Proc. R. Soc. Lond. B Biol. Sci. 2004, 271, S420-S422. [CrossRef] [PubMed]

29. Krause, J.; Hoare, D.; Krause, S.; Hemelrijk, C.K.; Rubenstein, D.I. Leadership in fish shoals. Fish Fish. 2000, 1, 82-89. [CrossRef]

30. Bisazza, A.; Dadda, M. Enhanced schooling performance in lateralized fishes. Proc. R. Soc. Lond. B Biol. Sci. 2005, 272, 1677-1681. [CrossRef] [PubMed]

31. Dadda, M.; Bisazza, A. Does brain asymmetry allow efficient performance of simultaneous tasks? Anim. Behav. 2006, 72, 523-529. [CrossRef]

32. Sovrano, V.A.; Dadda, M.; Bisazza, A. Lateralized fish perform better than nonlateralized fish in spatial reorientation tasks. Behav. Brain Res. 2005, 163, 122-127. [CrossRef] [PubMed]

33. Bibost, A.L.; Brown, C. Laterality influences cognitive performance in rainbowfish melanotaenia duboulayi. Anim. Cogn. 2014, 17, 1045-1051. [CrossRef] [PubMed]

34. Domenici, P.; Allan, B.; McCormick, M.I.; Munday, P.L. Elevated carbon dioxide affects behavioural lateralization in a coral reef fish. Biol. Lett. 2011. [CrossRef] [PubMed]

35. Domenici, P.; Allan, B.J.; Watson, S.-A.; McCormick, M.I.; Munday, P.L. Shifting from right to left: The combined effect of elevated $\mathrm{CO}_{2}$ and temperature on behavioural lateralization in a coral reef fish. PLoS ONE 2014, 9, e87969. [CrossRef] [PubMed]

36. Jutfelt, F.; de Souza, K.B.; Vuylsteke, A.; Sturve, J. Behavioural disturbances in a temperate fish exposed to sustained high- $\mathrm{CO}_{2}$ levels. PLoS ONE 2013, 8, e65825. [CrossRef] [PubMed]

37. Sundin, J.; Jutfelt, F. Effects of elevated carbon dioxide on male and female behavioural lateralization in a temperate goby. R. Soc. Open Sci. 2018, 5, 171550. [CrossRef] [PubMed]

38. Lopes, A.; Morais, P.; Pimentel, M.; Rosa, R.; Munday, P.; Gonçalves, E.; Faria, A. Behavioural lateralization and shoaling cohesion of fish larvae altered under ocean acidification. Mar. Biol. 2016, 163, 243. [CrossRef]

39. Nilsson, G.E.; Dixson, D.L.; Domenici, P.; McCormick, M.I.; Sørensen, C.; Watson, S.-A.; Munday, P.L. Near-future carbon dioxide levels alter fish behaviour by interfering with neurotransmitter function. Nat. Clim. Chang. 2012, 2, 201. [CrossRef]

40. Rosa, R.; Pimentel, M.; Galan, J.G.; Baptista, M.; Lopes, V.M.; Couto, A.; Guerreiro, M.; Sampaio, E.; Castro, J.; Santos, C. Deficit in digestive capabilities of bamboo shark early stages under climate change. Mar. Biol. 2016, 163, 60. [CrossRef]

41. Di Santo, V.; Bennett, W.A. Effect of rapid temperature change on resting routine metabolic rates of two benthic elasmobranchs. Fish Physiol. Biochem. 2011, 37, 929-934. [CrossRef] [PubMed]

42. McLaughlin, R.H.; O'Gower, A.K. Life history and underwater studies of a heterodont shark. Ecol. Monogr. 1971, 41, 271-289. [CrossRef] 
43. Rodda, K.; Seymour, R. Functional morphology of embryonic development in the port jackson shark heterodontus portusjacksoni (meyer). J. Fish Biol. 2008, 72, 961-984. [CrossRef]

44. Bisazza, A.; Pignatti, R.; Vallortigara, G. Laterality in detour behaviour: Interspecific variation in poeciliid fish. Anim. Behav. 1997, 54, 1273-1281. [CrossRef] [PubMed]

45. R Core Team. R: A Language and Environment for Statistical Computing, 3.4.3; R Foundation for Statistical Computing: Vienna, Austria, 2017.

46. Quaranta, A.; Siniscalchi, M.; Frate, A.; Iacoviello, R.; Buonavoglia, C.; Vallortigara, G. Lateralised behaviour and immune response in dogs: Relations between paw preference and interferon- $\gamma$, interleukin-10 and igg antibodies production. Behav. Brain Res. 2006, 166, 236-240. [CrossRef] [PubMed]

47. Siniscalchi, M.; Sasso, R.; Pepe, A.M.; Dimatteo, S.; Vallortigara, G.; Quaranta, A. Catecholamine plasma levels following immune stimulation with rabies vaccine in dogs selected for their paw preferences. Neurosci. Lett. 2010, 476, 142-145. [CrossRef] [PubMed]

48. Neveu, P.J. Cerebral lateralization and the immune system. In International Review of Neurobiology; Academic Press: Cambridge, MA, USA, 2002; Volume 52, pp. 303-323.

49. Jozet-Alves, C.; Viblanc, V.A.; Romagny, S.; Dacher, M.; Healy, S.D.; Dickel, L. Visual lateralization is task and age dependent in cuttlefish, sepia officinalis. Anim. Behav. 2012, 83, 1313-1318. [CrossRef]

50. Dharmaretnam, M.; Andrew, R.J. Age- and stimulus-specific use of right and left eyes by the domestic chick. Anim. Behav. 1994, 48, 1395-1406. [CrossRef]

51. Brown, C.; Gardner, C.; Braithwaite, V.A. Population variation in lateralized eye use in the poeciliid brachyraphis episcopi. Proc. R. Soc. Lond. Ser. B Biol. Sci. 2004, 271, S455-S457. [CrossRef] [PubMed]

52. Bisazza, A.; Facchin, L.; Pignatti, R.; Vallortigara, G. Lateralization of detour behaviour in poeciliid fish: The effect of species, gender and sexual motivation. Behav. Brain Res. 1998, 91, 157-164. [CrossRef]

53. Bibost, A.-L.; Kydd, E.; Brown, C. The effect of sex and early environment on the lateralization of the rainbowfish melanotaenia duboulayi. In Behavioral Lateralization in Vertebrates: Two Sides of the Same Coin; Csermely, D., Regolin, L., Eds.; Springer: Berlin/Heidelberg, Germany, 2013; pp. 9-24.

54. Rogers, L.J. Relevance of brain and behavioural lateralization to animal welfare. Appl. Anim. Behav. Sci. 2010, 127, 1-11. [CrossRef] 